\title{
Does Alumina Coating Alter the Solid Permeable Interphase Dynamics in $\mathrm{LiMn}_{2} \mathrm{O}_{4}$ Cathodes?
}

\author{
S. J. Rezvani,* R. Parmar, F. Maroni, F. Nobili, A. Di Cicco, and R. Gunnella
}

Cite This: J. Phys. Chem. C 2020, 124, 26670-26677

Read Online

\section{Solid Permeable Interface}

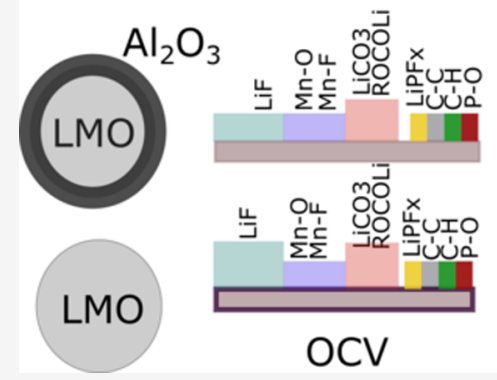

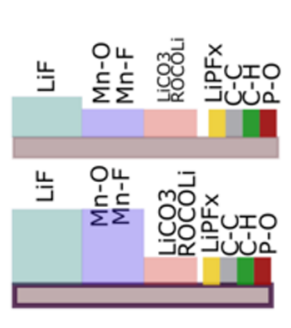

$4.35 \mathrm{~V}$

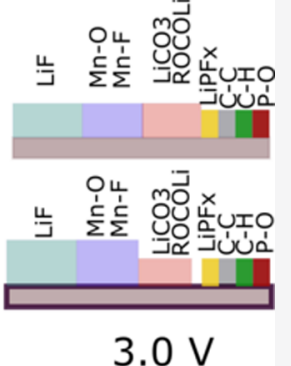

ABSTRACT: It is well known that the $\mathrm{Al}_{2} \mathrm{O}_{3}$ coating of the $\mathrm{LiMn}_{2} \mathrm{O}_{4}$ cathodes leads to improvement of the performance of these electrodes. However, the effect of the coating on the fundamental processes occurring on the interface with the active material which results in the formation of the solid permeable interphase is yet to be investigated. These effects should be more pronounced in the first cycle when a dynamic interaction of the active material at high voltage with the electrolyte and binder leads to the formation of this passivation layer. Here, we present a detailed investigation of the solid permeable interphase formation in alumina-coated and uncoated $\mathrm{LiMn}_{2} \mathrm{O}_{4}$ electrodes using X-ray absorption spectroscopy and analysis on the electrodes at the predesigned charging/ discharging states. We demonstrate that the alumina coating leads to modification of the solid permeable layer and its dynamics. We also discuss the possible influences of interface modifications via coating on the battery performance.

\section{INTRODUCTION}

The interfaces between the active material and the electrolyte solution are one of the most critical factors affecting the performance of lithium-ion battery electrodes. However, our current understanding of this key factor and its evolution and modulation remains limited. The battery electrodes often operate outside the voltage window of stability of the electrolyte, and hence, the electrolyte decomposition leads to the formation of a protective and insulating layer called the solid electrolyte interphase (SEI) on the anodes and solid permeable interphase (SPI) on the cathodes. ${ }^{1,2}$ The electron insulation caused by this passivation layer prevents further reduction/oxidation at the active material interfaces, leading to a stable and operative electrode, while its ionic conductivity facilitates the $\mathrm{Li}^{+}$diffusion for battery operation. It is known that the decomposition of the electrolyte salt initiates almost instantly, and the passivation layers are believed to be formed, mainly, within the first cycle of the battery operation. ${ }^{2-4}$ However, the formation of this layer could be limited in lithium-ion battery cathode materials that may result in an extensive deterioration of the active material and severe ageing of the battery electrodes. Hence, one of the main investigation on batteries, capacitors, and supercapacitors aims to optimize the interface processes of the reversible ion uptake and to limit the material deterioration during the cycling. ${ }^{4-7}$

It is known that nanomaterials exhibit enhanced physicochemical peoperies, ${ }^{8-10}$ from which the layered and olivinestructured materials and in particular $\mathrm{LiCoO}_{2}, \mathrm{LiNi}_{x} \mathrm{Mn}_{y} \mathrm{C}_{z} \mathrm{O}_{2}$, and $\mathrm{LiFePO}_{4}$ are among the most promising and efficiently implemented cathode materials ${ }^{11-13}$ despite their main drawbacks as weight per stored energy, aging, and cyclability. ${ }^{14,15}$ Out of these materials, lithium manganates are perfect candidates to reduce such limitations. ${ }^{11}$ Ideally, the stoichiometric spinel $\mathrm{LiMn}_{2} \mathrm{O}_{4}(F d \overline{3} m)$ has a crystal structure with general formula $\mathrm{A}\left[\mathrm{B}_{2}\right] \mathrm{O}_{4}$, where $\mathrm{A}$ and $\mathrm{B}$ are divalent and trivalent ions in tetrahedral $T_{d}$ symmetry $\left(\mathrm{Li}^{+}\right.$ions in the $8 \mathrm{a}$ tetrahedral site) and octahedral $\mathrm{D}_{3 d}$ symmetry $\left(\mathrm{Mn}^{+}\right.$ions $16 \mathrm{~d}$ site), respectively. Oxygen anions in these structures occupy the cubic close-packed $\mathrm{C}_{3 v}$ (32e site) symmetry. ${ }^{16,17}$ However,

Received: September 16, 2020

Revised: November 17, 2020

Published: November 27, 2020

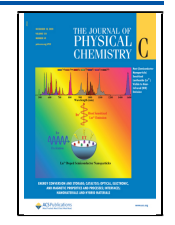


instabilities in the spinel crystal structure because of ionic elongation (e.g., Jahn-Teller distortion), within the charging cycle, have been observed. ${ }^{18}$

Use of $\mathrm{LiMn}_{2} \mathrm{O}_{4}$ as an economic and safe substitute of $\mathrm{LiCoO}_{2}$ in positive electrodes would be encouraging for the future improvements of safety and environment impact in all its applications. Manganese can be reduced less efficiently than cobalt $(\mathrm{Co}),{ }^{11}$ and for this reason, a strong interest in using $\mathrm{LiMn}_{2} \mathrm{O}_{4}$ (LMO) as the safe electrode substitute is more and more rising. However, it is known that the $\mathrm{Mn}^{3+}$ valence ${ }^{19}$ during battery discharging at low voltages is subjected to $\mathrm{Mn}$ disproportion and consequent dissolution of $\mathrm{Mn}^{2+}$ which leads to an accelerating capacity fading. ${ }^{20}$ It has been previously shown that the alumina coating on the $\mathrm{LiMn}_{2} \mathrm{O}_{4}$ improves the performance and functionality of these electrodes. ${ }^{12}$ The enhancement of the electrode operation has been also observed in the case of the effective carbon coating of the $\mathrm{LiZnFe}_{2} \mathrm{O}_{4}$ anode material. However, in the case of the anode material with a thick solid electrolyte interphase layer, the carbon coating is suggested to facilitate the agglomeration of the nanoparticles and providing a homogenous electrode surface, ${ }^{21}$ in the case of the cathodes with a relatively thin solid permeable layer, the coating can alter completely the decomposition and formation of the SPI layer. Hence, an investigation of the coating effect on the SPI formation and dynamics during cycling can significantly improve our understanding of the coating effects on the battery performance.

Soft X-ray absorption spectroscopy (XAS) is a very useful technique to determine the atomic and the electronic structure close to the surface because of its short-range probing depth. XAS facilitates the investigation of the static and dynamic short-range structure with a tunable probing depth in the range 3-100 nm with minimal destructive effects. ${ }^{22}$ XAS can prevent the degradation of the components of the passivating layer, while confirming the overall picture of inorganic components occupying the region close to the active particles and of organic ones occupying the external zone. ${ }^{3,22,23}$ Thus, XAS can help us investigate the effect of the coating on the superficial passivating layer dynamics and its consequent participation in the stabilization of the electrode performance. In this work, we have focused on the formation and evolution of the superficial passivating layer in the LMO cathodes and the effect of the alumina coating on the dynamics and stabilization of the SPI layer. The consequent modification of the battery performance because of the modulation of the SPI dynamics via coating is also discussed.

\section{EXPERIMENTAL SECTION}

Material synthesis and electrode preparation process of $\mathrm{Al}_{2} \mathrm{O}_{3}-$ $\mathrm{LiMn}_{2} \mathrm{O}_{4}$ followed the solid-state method used in ref 24. As reported by Pasqualini et al., ${ }^{12}$ the method included milling and calcination at $400{ }^{\circ} \mathrm{C}$ for $10 \mathrm{~h}$ of $\mathrm{Li}_{2} \mathrm{CO}_{3}$ and $\mathrm{MnCO}_{3}$ and subsequent regrounding and calcination at $750{ }^{\circ} \mathrm{C}$ for $48 \mathrm{~h}$. Few nanometers of $\mathrm{Al}_{2} \mathrm{O}_{3}$ coating ( 3 wt \%) were obtained by the co-precipitation route method; ${ }^{25}$ the $\mathrm{LiMn}_{2} \mathrm{O}_{4}$ powder was added to $0.02 \mathrm{M}$ solution of $\mathrm{Al}\left(\mathrm{NO}_{3}\right)_{3} \cdot 9 \mathrm{H}_{2} \mathrm{O}$ in deionized water, stirred with adding ammonia solution to obtain $\mathrm{Al}(\mathrm{OH})_{3}$ in precipitation. The slurry was then separated and washed with deionized water and dried at $40{ }^{\circ} \mathrm{C}$ temperature in vacuum. Uniform $\mathrm{Al}_{2} \mathrm{O}_{3}$ coating of $\mathrm{LiMn}_{2} \mathrm{O}_{4}$ is obtained after calcination at $450{ }^{\circ} \mathrm{C}$ temperature (with $10{ }^{\circ} \mathrm{C} / \mathrm{min}$ heating and cooling rate) for $120 \mathrm{~min}$ in air (see Supporting Information and Ref 12.).

Electrodes (diameter $9 \mathrm{~mm}$ ) have been prepared by casting an aqueous slurry containing the active material (uncoated or $\mathrm{Al}_{2} \mathrm{O}_{3}-\mathrm{LiMn}_{2} \mathrm{O}_{4}$ ), binder (Na-carboxymethyl cellulose, NaCMC by Sigma-Aldrich), and conductive, amorphous carbon (SuperC65 by Timcal) of active material/binder/carbon in a mass ratio of $80: 10: 10$, respectively. The slurry was stirred for $6 \mathrm{~h}$ and transferred to the $\mathrm{Al}$ foil current collector using the Doctor Blade technique with $200 \mu \mathrm{m}$ thickness, subsequently dried at room temperature overnight, and finally dried at 120 ${ }^{\circ} \mathrm{C}$ for $12 \mathrm{~h}$ in vacuum. The active material in the electrode was $2 \mathrm{mg} \mathrm{cm}^{-1}$. For counter and reference electrodes, lithium metal was used, separated by glass fiber (Whatman GF/A), in $1 \mathrm{M}$ $\mathrm{LiPF}_{6}$ in the EC/DMC $(1: 1 \mathrm{v} / \mathrm{v})$ electrolyte.

The Raman spectra have been recorded by "HORIBA" micro-Raman spectroscopy with a green laser light source $(\lambda=$ $532 \mathrm{~nm}$ ), 600 lines/mm grating system, and $50 \times$ objective lens at ambient conditions. The spectrometer was calibrated by pure crystalline Si signals and averaged several points on the samples. All the Raman spectra were recorded in the range from 0 to $3000 \mathrm{~cm}^{-1}$ with $30 \mathrm{~s}$ of the acquisition time. For Xray absorption near-edge spectroscopy (XANES), electrodes were dried in an Ar atmosphere and kept in sealed packs while transported to the measurement chambers. Then, the samples were placed in the experimental chambers via an argon-filled load lock chamber. Soft XAS experiments were carried out using radiation at the exit of the 8.1 bending magnet of the ELETTRA synchrotron facility in Trieste (Italy) (BEAR endstation BL8.1L). The spectral energy was calibrated by referring to carbon $\pi-\pi^{*}$ transitions. The incident light was horizontally polarized, and the incidence angle of the light with respect to the sample surface plane was kept fixed at $45^{\circ}$ with the $\mathrm{s}$ polarization. XAS measurements were done in total electron yield (TEY) mode and total fluorescence yield mode (TFY) with distinctive mean probing depths and were normalized to the incident photon flux. ${ }^{22}$

For both uncoated and $\mathrm{Al}_{2} \mathrm{O}_{3}$-coated $\mathrm{LiMn}_{2} \mathrm{O}_{4}$ materials, the following samples have been prepared: open-circuit potential electrode in contact with the electrolyte for $t=20 \mathrm{~h}$ (point labeled as OCV in Figure 1, E = 3.2-3.3 V for all electrodes);

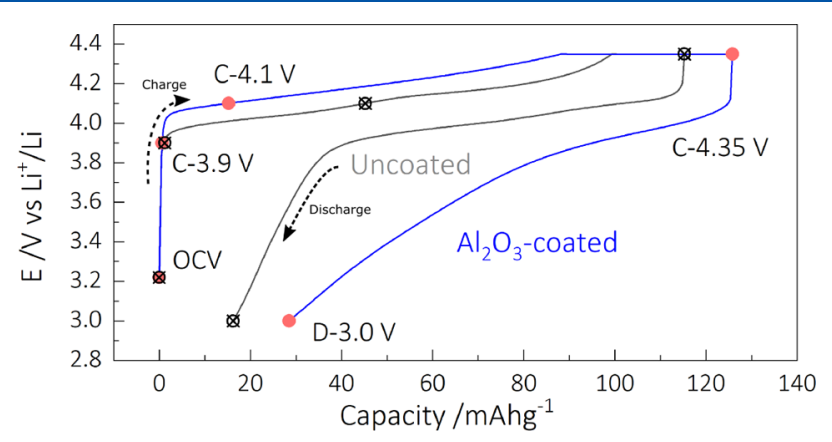

Figure 1. Electrochemical conditioning of uncoated and aluminacoated $\mathrm{LiMn}_{2} \mathrm{O}_{4}$ electrodes at different states of charges.

charging half-cycle electrodes at $E=3.95 \mathrm{~V}(\mathrm{C}-3.9 \mathrm{~V})$ and $E=$ 4.1 V (C-4.1 V) in Figure 1; fully charged electrodes at $E=$ $4.35 \mathrm{~V}$ (C-4.35); fully discharged electrodes after the first cycle, at $E=3 \mathrm{~V}(\mathrm{D}-3 \mathrm{~V})$; electrodes in the fully discharged state after prolonged cycling $(100$ cycles at $E=3 \mathrm{~V})$. The charge steps were applied at constant current (1C rate, 

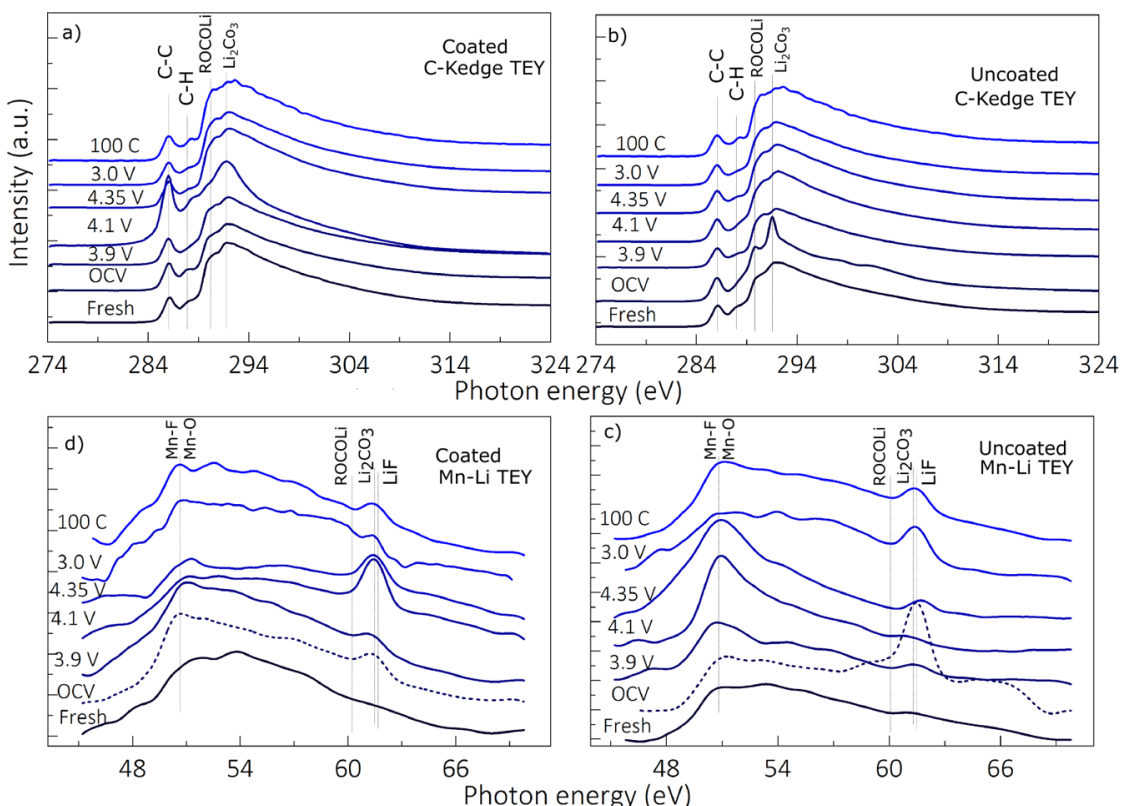

Figure 2. (a,b) C K-edge TEY spectra of $\mathrm{Al}_{2} \mathrm{O}_{3}$ coated (a) and uncoated (b) LMO samples at different values of potential during the voltammetry characterization; (c,d) Li K-edge TEY spectra of coated (c) and uncoated (d) samples at selected stages.

corresponding to $\left.I=148 \mathrm{~mA} \mathrm{~g}^{-1}\right)$, followed by a constantpotential equilibration step (the current was left to decay below $C / 20$, corresponding to $I=7.5 \mathrm{~mA} \mathrm{~g}^{-1}$ ). The discharge half-cycles were always performed at constant current (1C rate) without any final constant-potential steps. All potentials versus the $\mathrm{Li}^{+} / \mathrm{Li}$ redox couple are given. The electrochemical behavior of the electrodes at different cycles are reported in the Supporting Information and in more detail in ref 12.

\section{RESULTS AND DISCUSSION}

The XAS method is very efficient to find out the local crystal structure of the specified element inside the complex compound material providing interface short-range sensitivity in TEY mode, with mean probing depth (MPD) around 5$10 \mathrm{~nm}$, by detecting the total collected current on the electrode. On the other hand, bulk sensitivity by TFY mode $(\mathrm{MPD} \sim 100 \mathrm{~nm})^{22}$ can be obtained by the emitted fluorescence in response to the core excitation. The XAS spectra of the carbon K-edge in coated and uncoated electrodes are shown in Figure 2a,b.

The spectra evidence several components with their evolution clearly visible at different charging and discharging stages. In the coated samples, the first observable components at around $285 \mathrm{eV}$ are attributed to the $\mathrm{C}-\mathrm{C}$ bonds present within the cellulose-based binder and the conductive hard carbon used to fabricate the electrodes along with a component at around $287 \mathrm{eV}$ which can be assigned to the $\mathrm{C}-\mathrm{H}$ bonds also present in the electrode because of the presence of the binder and of solvent decomposition products (see eq 2). ${ }^{4,26}$ These components retain the stable features of SPI formation on the electrodes. On the other hand, there are other two major components observed at around 290 and 292 $\mathrm{eV}$ that correspond to the formation of the lithium carbonate and alkyl lithium carbonate. ${ }^{27-29}$ Lithium carbonate and alkyl lithium carbonates are the side products of the solvent/binder reactions (specially with the electrolyte salts) on the surface of the electrodes as shown in the following equations

$$
\begin{aligned}
& (\mathrm{DMC}) \mathrm{CH}_{3} \mathrm{OCO}_{2} \mathrm{CH}_{3}+e^{-}+\mathrm{Li}^{+} \\
& \quad \rightarrow \mathrm{CH}_{3} \mathrm{OCO}_{2} \mathrm{Li} \downarrow+\mathrm{CH}_{3} \\
& 2 \mathrm{ROCO}_{2} \mathrm{Li}+\mathrm{H}_{2} \mathrm{O} \rightarrow \mathrm{Li}_{2} \mathrm{CO}_{3}+2 \mathrm{ROH}+\mathrm{CO}_{2}
\end{aligned}
$$

The formation of these components usually initiates as early as the fabrication of the electrodes and in particular in contact with the electrolyte. ${ }^{4,23}$ In the coated samples, the carbonate formation is reduced at $4.1 \mathrm{~V}$ of the charging half-cycle. This is evidenced by the decrease of the carbonate component ratio in comparison with the constant $\mathrm{C}-\mathrm{C}$ component of the electrode in the spectra. Moreover, the different higher energy tail of the spectra can be also modulated because of such reduction and domination of the $\mathrm{C}-\mathrm{C}$ component. In further stages, increasing the potential to $4.35 \mathrm{~V}$ (Figure 2a), the carbonate formation increases again (visible by the increase of the carbonate ratio) and persists also within the discharge halfcycle. The reversibility of carbonate components has been observed in the carbonate and alkyl carbonate superficial layers of the SEI of the anode materials for which the highest carbonate formation occurs at the lithiation half cycle. ${ }^{4}$ The organic layer reversibility is also suggested to be further favored in the presence of metallic components (e.g., aluminum in this case). ${ }^{30}$ On the other hand, in the uncoated electrodes, while a similar formation of the components is visible, the highest carbonate formation is observed at the open circuit stage (OCV). This difference can be because of the absence of the alumina coating which causes the active material to be in direct reaction with the electrolyte even at open-circuit voltage. The reversibility of the gel-type layer is hindered in uncoated samples as it can be seen by the unmodified shape of the C Kedge in the whole cycle.

The spectra of the Li K-edge (overlapped with Mn M-edge) are presented in Figure 2c,d. They show the major components at $49.2,60.1,61.2$, and $61.5 \mathrm{eV}$, while the fresh electrodes show broad spectra with hindered features. In contact with the electrolyte, an increase in the components at around $61 \mathrm{eV}$ and around $49.2 \mathrm{eV}$ is observed. These components can be 

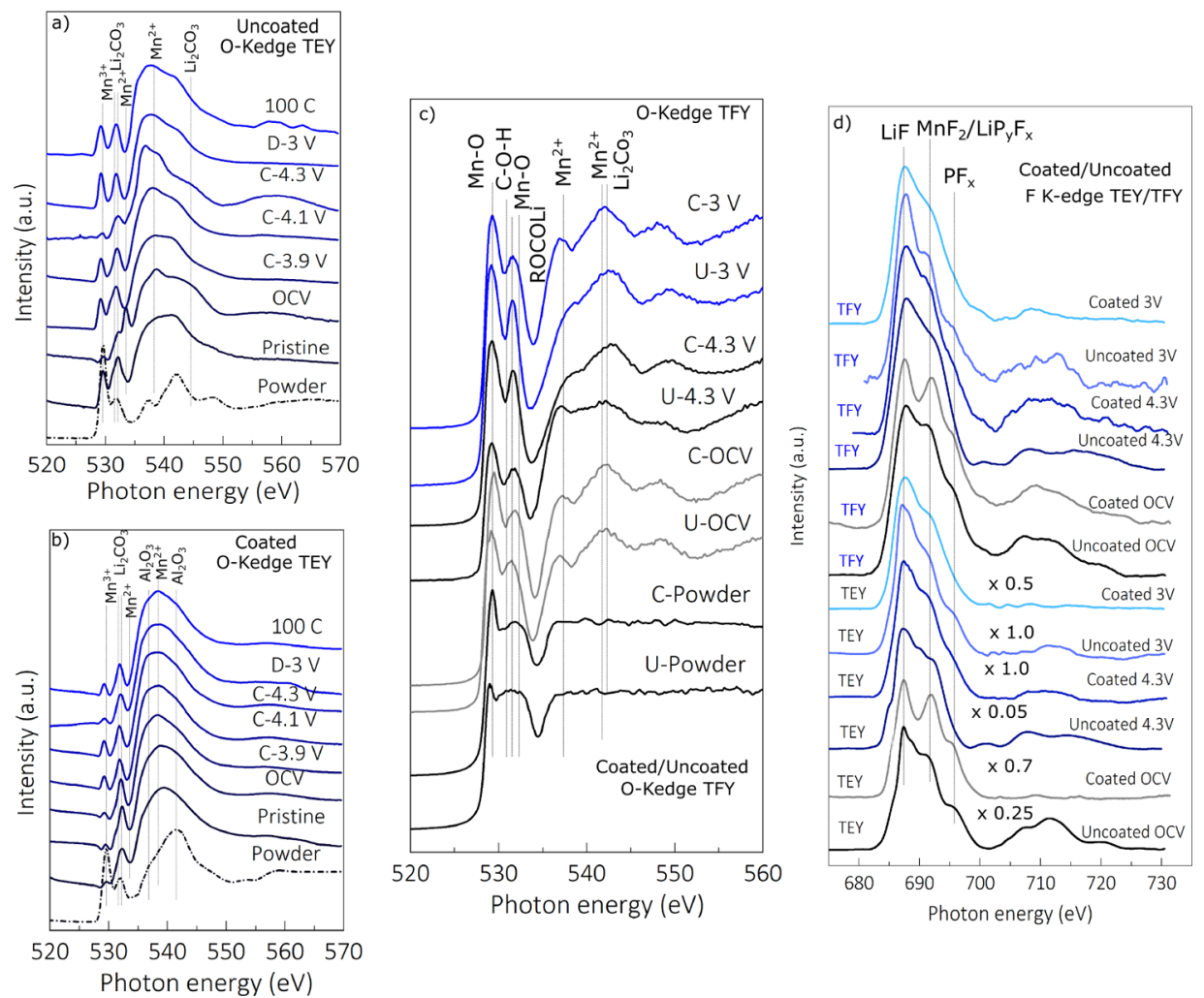

Figure 3. a,b) O K-edge TEY mode, spectra of $\mathrm{Al}_{2} \mathrm{O}_{3}$ coated and uncoated LMO samples at different charging (C) and discharging (D) values of potential during the voltammetry characterization; (c) O TFY mode spectra of coated (C) and uncoated (U) samples at selected stages; (d) F kedge spectra in TEY and TFY modes of the selected potential points of coated (C) and uncoated (U) electrodes.

attributed to the formation of $\mathrm{LiF}$ together with oxidation/ fluorination of the manganese component, respectively, which can be observed here because of the overlap of the Mn M-edge with the Li K-edge. ${ }^{31-33}$ Contrary to other structures such as $\mathrm{ZnFe}_{2} \mathrm{O}_{4}$ or $\mathrm{Li}_{4} \mathrm{Ti}_{5} \mathrm{O}_{12}$, an increase of the formation/ precipitation of $\mathrm{Li}-\mathrm{O}$ (at around $58 \mathrm{eV}$ ) is not observed in our case. ${ }^{32,33}$ This can be either because of the absence of the precipitated or dissolved $\mathrm{Li}-\mathrm{O}$ component or screening of the small ratio $\mathrm{Li}-\mathrm{O}$ formation by the intrinsic component of the active material. Meanwhile, a persistent increase of the components at around $61 \mathrm{eV}$ is clear in the electrodes while in contact with the electrolyte and during the charging/ discharging cycle. These components can be associated with the formation of the LiF, lithium carbonate, and alkyl lithium carbonate. The alkyl lithium carbonate shows a minimal presence, while because of the overlap of the $\mathrm{LiF}$ and $\mathrm{Li}_{2} \mathrm{CO}_{3}$, the exact participation of each component cannot be separated, though in agreement with the $\mathrm{C}$ K-edge, the decrease of the carbonate is expected at the $4.1 \mathrm{~V}$ in the coated samples. Hence, this feature can be mainly be related to the formation of further LiF components. On the other hand, the uncoated samples show a completely distinctive evolution compared with the coated ones. In these samples, the dominant increase of the $\mathrm{Mn}-\mathrm{O} / \mathrm{Mn}-\mathrm{F}$ formation is clearly observable in the charging half cycle, while the transition of $\mathrm{LiF} / \mathrm{Li}_{2} \mathrm{CO}_{3}$ is peaked at OCV and discharging half cycle, in agreement with the carbon K-edge spectra. These results suggest a strong participation of the active material in the formation of the SPI layer in the uncoated samples.

Looking at the spectra of the samples taken at the oxygen Kedge from the pristine powder of coated and uncoated samples, the alumina coating feature is also clearly visible in the alumina-coated sample TEY spectra between 539 and 543 $\mathrm{eV} .{ }^{34}$ Upon charging/discharging (see Figure 3), two main components at 529 and $531 \mathrm{eV}$ corresponding to the $\mathrm{Mn}-\mathrm{O}$ $\left(\mathrm{Mn}^{3+}\right)$ phases of the active material are evident. The intense pre-edge components at around 529 and $532 \mathrm{eV}$ correspond to the transition of oxygen $1 \mathrm{~s}$ electron to the hybridized state of $\mathrm{Mn} 3 \mathrm{~d}$ and oxygen $2 \mathrm{p}$ orbitals with high-spin electronic configuration under octahedral $(\mathrm{Oh})$ symmetry, ${ }^{35}$ corresponding to the transition to an unoccupied molecular level which has Mn 3d-oxygen $2 \mathrm{p}$ character.

These states are expected to be quenched and also pushed to a higher transition energy when valence is reduced. In particular, in $\mathrm{MnO}$, the additional $\mathrm{Mn}$ electrons occupy up to half of the empty state while the gap is significantly increased. The quenching of this feature (i.e., $529 \mathrm{eV}$ ) identifies the formation of $\mathrm{Mn}^{2+}$ within the cycling process. As it is seen from the TEY measurements, this component is hindered by increasing the charging potential to the $4.35 \mathrm{~V}$ in the uncoated samples, contrary to the coated samples which suggest lower formation of $\mathrm{Mn}^{2+}$. The quenched intensity of this component at OCV can be related to the chemical redox of the active material in contact with the electrolyte prior to the initiation of the electrochemical redox process. A simultaneous enhancement of the state at $537 \mathrm{eV}$ is clear in $\mathrm{O}-\mathrm{K}$ edge spectra allowing to recognize the signatures of $\mathrm{Mn}^{2+}$ valence in the bulk (as observed in $\mathrm{MnO}$, O K XAS spectra $^{36}$ ) when the electrochemical potential of $4.35 \mathrm{~V}$ is applied to the electrode. However, the uncoated sample evidences a more vigorous formation of $\mathrm{Mn}^{2+}$ compared with the coated sample in contact with electrolyte at OCV (visible by the presence of an intense shifted feature of $\mathrm{Mn}^{2+}$ at around $534 \mathrm{eV}$ ) which identifies the protective effect of the coating. 
Furthermore, a comparison between the TEY and TFY spectra shows a higher degree of the oxidation and carbonate species (e.g., $\mathrm{Li}_{2} \mathrm{CO}_{3}$ and $\mathrm{ROCOLi}$ ) on the surface of uncoated electrodes.

On the other hand, the F K-edge spectra (TEY and TFY) of the samples at the selected specific potential points (charge/ discharge extreme points) are shown in Figure 3d. There are three main components evident in these spectra at 684,689 , and $696 \mathrm{eV}$. The component at $684 \mathrm{eV}$ can be attributed to the $\mathrm{LiF}$ species, formed from the decomposition of the electrolyte at its interface with LMO nanoparticles, being a dominant component of the passivating layer, in agreement with the $\mathrm{Li}$ K-edge spectra. ${ }^{29}$ The second component can be assigned to the $\mathrm{LiPF}_{x}$ or $\mathrm{LiPOF}_{x}$ phases resulted from the residues of the electrolyte in the passivating layer as well as $1 \mathrm{~s} \downarrow$ to $t_{2} g \downarrow$ and 1s $\downarrow$ to $\mathrm{e}_{\mathrm{g}} \downarrow$ transitions as characteristic behavior of $\mathrm{Mn}^{2+}$ valency. ${ }^{37,38}$ The third component can be assigned either to the absorption in the continuum or to the formation of the $\mathrm{PF}_{x}$. The TFY spectra of the samples also follow a trend similar to that of the TEY signal, indicating absence of the fluorine components within the active material bulk structure (see Figure 3d) and observation of the SPI of the deeper layers of the porous electrodes without bulk-like (modified) fluorine components. The intensity of the TEY spectra is significantly different at each stages of the charge or discharge, as indicated in Figure 3d with a multiplication factor. The intensity corresponds directly to the present quantity of $\mathrm{F}$ atoms within the SPI structure. A larger amount of the fluorine components observed in uncoated samples at $4.35 \mathrm{~V}$ indicates a larger redox of the active material in these electrodes resulting in formation of $\mathrm{Mn}-\mathrm{F}$ species, as also observed by $\mathrm{Mn}$ M-edge features. The formation of $\mathrm{Mn}-\mathrm{F}$ species is confirmed by the P K-edge spectra taken at the fully charged and fully discharged potential values (see Figure 4). Because the coated and uncoated

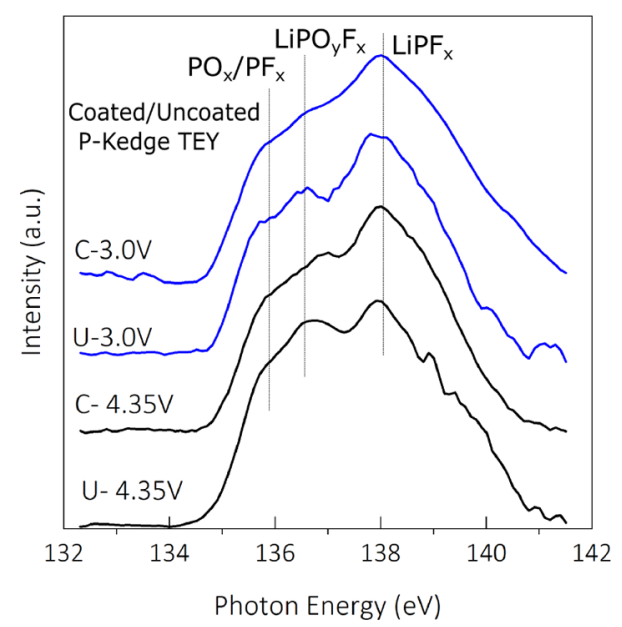

Figure 4. X-ray absorption spectra of the $\mathrm{P}$ K-edge of the coated (C) and uncoated $(\mathrm{U})$ samples at charging/discharging extreme points $(4.35 \mathrm{~V} / 3.0 \mathrm{~V})$ measured in total electron yield mode.

electrodes at both stages show relatively similar electrolyte decomposition salt precipitations, the increase in the F K-edge can be reasonably correlated to the formation of the $\mathrm{Mn}-\mathrm{F}$ species. On the other hand, the $\mathrm{LiF}$ compound is formed especially at high voltage because of the instability of the electrolyte and the redox processes in the case of uncoated samples. On the contrary in the coated samples, LiF is formed very early in the first cycle, showing a semireversible behavior and stabilizes at the end of the first cycles as expected and in agreement with ref 39 .

$\mathrm{LiF}$ formation is expected in all samples via the decomposition of the electrolyte as

$$
\mathrm{LiPF}_{6} \leftrightarrow \mathrm{LiF}+\mathrm{PF}_{5}
$$

the water contamination/side products can result in the formation of the HF and finally in an increase of the side production of the $\mathrm{LiF}$ as follows

$$
\begin{aligned}
& \mathrm{PF}_{5}+\mathrm{H}_{2} \mathrm{O} \rightarrow 2 \mathrm{HF}+\mathrm{POF}_{3} \\
& 2 \mathrm{POF}_{3}+3 \mathrm{Li}_{2} \mathrm{O} \rightarrow \mathrm{P}_{2} \mathrm{O}_{5}+6 \mathrm{LiF}
\end{aligned}
$$

Furthermore, the formation of the HF as a side product can also result in formation of $\mathrm{MnF}_{2}$ as follows

$$
\mathrm{Mn}^{2+}+2 \mathrm{HF} \leftrightarrow \mathrm{MnF}_{2}+2 \mathrm{H}^{+}
$$

These results demonstrate a clear modification of the SPI composition and dynamics triggered by the presence of alumina coating, possibly by the modification of the electrolyte decomposition on the active material. As briefly discussed before, the P K-edge exhibits three main excitations at around 135.7, 136.5, and $137.8 \mathrm{eV}$. These components can be associated to the $\mathrm{P}-\mathrm{O} / \mathrm{P}-\mathrm{F}, \mathrm{LiPOF}$, and $\mathrm{LiPF}$ species, precipitated on the SPI interface via the decomposition of the electrolyte salt as indicated in eqs $3-5$ and 7 and 8 below

$$
\begin{aligned}
& \mathrm{PF}_{5}+2 x \mathrm{Li}^{+}+2 x e^{-} \rightarrow \mathrm{Li}_{x} \mathrm{PF}_{5-x} \downarrow+x \mathrm{LiF} \downarrow \\
& \mathrm{POF}_{3}+2 x \mathrm{Li}^{+}+2 e^{-} \rightarrow \mathrm{Li}_{x} \mathrm{POF}_{3-x} \downarrow+x \mathrm{LiF} \downarrow
\end{aligned}
$$

The component ratio remains similar in both coated and uncoated samples as well as within the charging and discharging half cycles. This indicates a relative constant participation of the electrolyte phosphorus residue within the SPI interphase in these electrodes.

In order to confirm the bulk composition of the SPI layers, we employed micro-Raman spectroscopy with a relatively higher spatial resolution compared with the XAS (see Experimental Section). Figure 5 shows the Raman spectra of $\mathrm{Al}_{2} \mathrm{O}_{3}$-coated (left) and uncoated (right) $\mathrm{LiMn}_{2} \mathrm{O}_{4}$ electrode samples from 0 to $3000 \mathrm{~cm}^{-1}$ wavenumber range. Fresh coated and uncoated LMO powder samples show similar Raman spectra, where Raman shifts at $\sim 310,360$ ( $\mathrm{E}_{\mathrm{g}}$ and $\mathrm{F}_{2 \mathrm{~g}}$ modes), and $\sim 650 \mathrm{~cm}^{-1}\left(\mathrm{~A}_{1 \mathrm{~g}}\right.$ mode $)$ are assigned to $\mathrm{Li}-\mathrm{O}$ or $\mathrm{Li}-\mathrm{OH}$ and $\mathrm{Mn}-\mathrm{O}$ bonds vibration in tetrahedral and octahedral symmetries of the spinel structure, respectively. Upon fabrication of the electrodes and within the cycling, the $\mathrm{Li}-$ $\mathrm{C}-\mathrm{O}$ bond vibrations in the $\mathrm{Li}_{2} \mathrm{CO}_{3}$ compound at $\sim 280,470$, and $1100 \mathrm{~cm}^{-1}$ wavenumbers appear specially in the uncoated fresh electrode which shows a significant spectral broadening at both $\sim 470 \mathrm{~cm}^{-1}$ and around $1200 \mathrm{~cm}^{-1}$ in agreement with the higher formation of the carbonate species on the uncoated sample. Furthermore, upon cycling, the main peak related to $\mathrm{Mn}-\mathrm{O}$ bond vibrations in octahedral unit $\mathrm{MnO}_{6}^{-}$shifted to a lower wavenumber of $\sim 610 \mathrm{~cm}^{-1}$ with spectral broadening at $\sim 500-580 \mathrm{~cm}^{-1}$, corresponding to layered delithiated phase (e.g., $\mathrm{Li}_{1+x} \mathrm{Mn}_{2} \mathrm{O}_{4}$ or $\mathrm{LiMnO}_{2}$ ) and multication vibrations of $\mathrm{Mn}^{4+/ 3+}-\mathrm{O}$ bonds in the defective spinel LMO phase. ${ }^{16,40,41} \mathrm{~A}$ phase transformation from the layered LMO phase at lower potentials (up to $3.9 \mathrm{~V}$ ) to a $\lambda-\mathrm{MnO}_{2}$ phase in spinel structure $^{16,17,42}$ at higher potentials in agreement with the lithiation/delithiation procedure is clearly visible in the case of 

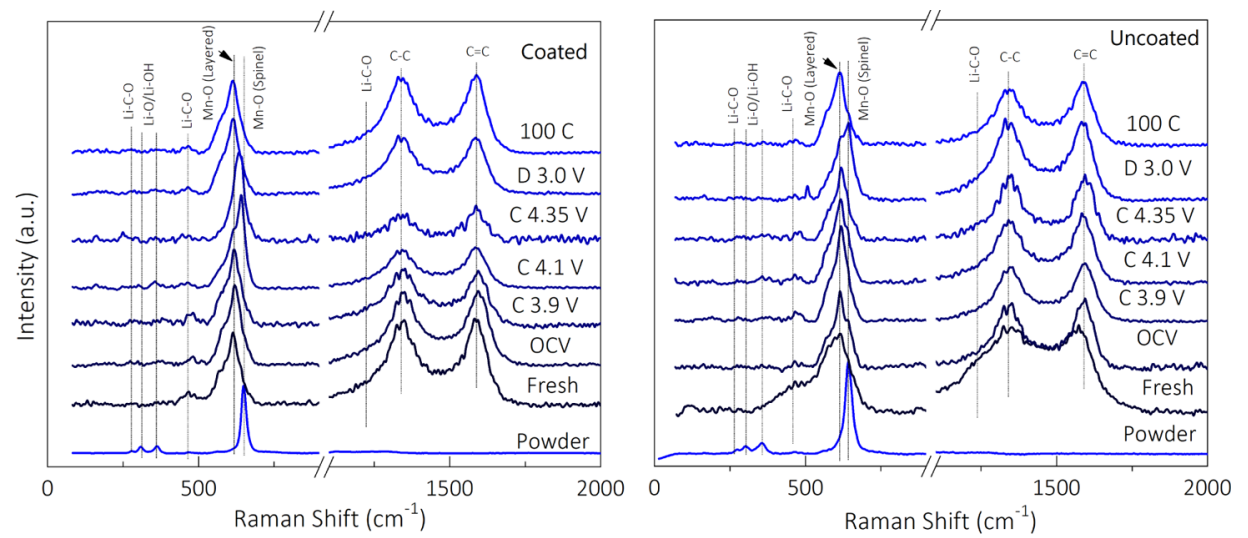

Figure 5. Micro-Raman analysis of $\mathrm{Al}_{2} \mathrm{O}_{3}$ coated (left panel) and uncoated (right panel) LMO samples at different charging (C) and discharging (D) values of potential during the voltammetry characterization.

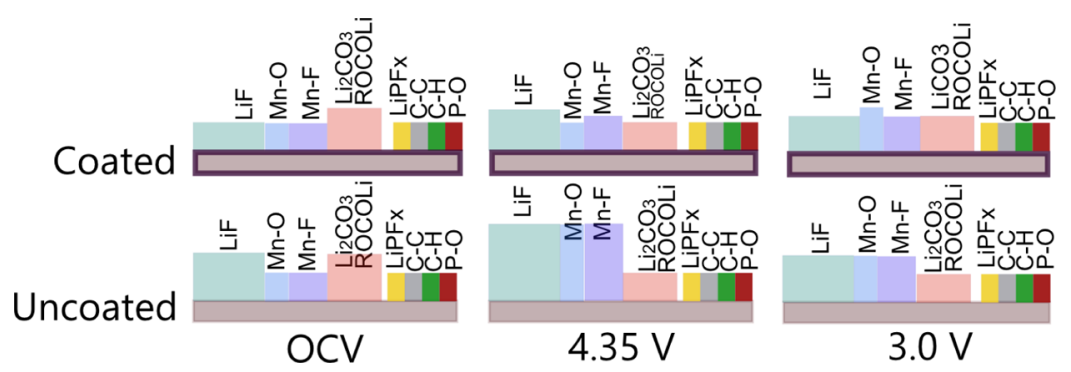

Figure 6. Qualitative schematics of the formation and dynamics of the solid permeable interphase formed on the uncoated and alumina-coated $\mathrm{LiMn}_{2} \mathrm{O}_{4}$ cathodes at extremity of the charging/discharging of the first cycle.

coated samples. However, this transformation is disrupted in the case of the uncoated samples apart from the discharged (lithiatated) electrode at $3.0 \mathrm{~V}$ that reveals a hint of a reversal to the spinel structure, and the electrodes at all stage show a defected layered LMO structure that can be the result of the $\mathrm{Mn}-\mathrm{F} / \mathrm{Mn}-\mathrm{O}$ formations.

Finally, components at higher Raman shift values at around $\sim 1350$ and $\sim 1590 \mathrm{~cm}^{-1}$ can be assigned to the D-band (C-C bond vibrations, $A_{g}$ mode) and $G$-band ( $E_{g}$ mode), which correspond to $\mathrm{C}-\mathrm{C} / \mathrm{C}=\mathrm{C}$ stretching vibrations in lattice of the carbons in the electrode, respectively. Raman analysis of the carbon component of the spectra can be done by using intensity ratio $\left(I_{\mathrm{D}} / I_{\mathrm{G}}\right)$ and integral area ratio $\left(A_{\mathrm{D}} / A_{\mathrm{G}}\right)$ of $\mathrm{D}$ and $\mathrm{G}$ bands that provide insights into the evolution of the carbon phase formation as well as increase/decrease of the defect formation in the carbonaceous structure of the electrodes. In our case of coated and uncoated LMO samples, the $I_{\mathrm{D}} / I_{\mathrm{G}}$ intensity ratio remains relatively constant (within the error limit) with respect to potential that can signify the uniform presence of disordered carbonaceous elements within the electrodes. However, broadenings can be observed in these components particularly at around $1100-1200 \mathrm{~cm}^{-1}$. The peak broadening at $\sim 1360,1470,1480$, and $1200 \mathrm{~cm}^{-1}$ Raman shift values is usually related to $-\mathrm{CH}_{2}$ scissor mode vibrations (e.g., polyethylene and polyethylene oxide species formation) and $\mathrm{Li}-\mathrm{C}-\mathrm{O}$ formation, respectively, related to the carbonate and alkyl carbonate formations, ${ }^{43}$ in agreement with the XAS results.

\section{CONCLUSIONS}

In the battery electrodes, a semireversible dynamics is expected upon the charging/discharging cycle, that is, in our case reduction and oxidation of the manganese oxide structure. Based on our analysis, this process is interrupted strongly in LMO electrodes via the deterioration of the active material and decomposition of the electrolyte salt which results in alteration of the passivating interphase layer. We have shown that in a comparison between the alumina-coated electrode and the uncoated electrode, the active material dynamic is preserved, while the particles are protected by the coating layer. The SPI layer formed on the coated samples follows the expected behavior as a function of the potential that the electrode is subject to and consequently remains stable. An irreversible organic top layer consisting of the lithium carbonate and alkyl lithium carbonate was also observed in these electrodes. On the contrary, the SPI layer formed on the uncoated electrodes exhibits extreme decomposition of the electrolyte and formation of the large amount of the side products with a significant contribution of the active material decomposition (see Figure 6). The SPI layer in this case does not follow the expected cycling behavior and does not preserve the consistency of the active material. The carbonate formation does not follow the expected irreversibility neither. The extreme formation of the irreversible lithium and manganese fluorides in these electrodes indicate the deactivation of a large portion of the active materials which leads to a significant deterioration of the electrode. The instability of the SPI layer formed on the uncoated electrodes, furthermore, might not sufficiently passivate the superficial layers and hence does not isolate the active materials from continuous oxidations. This leads to a strong irreversibility of the active material redox process and further hindrance of the battery performance. Though it might stabilize after many cycles, its dynamics results in a significant active material depletion. Our analysis suggest that in some structures such as the LMO, the SPI 
layers cannot passivate the active materials effectively or the passivation leads to the consumption of a large portion of the active material. This can probably be because of the low thickness of the passivation layer formed at the interface (in our case, it has been shown that the SPI can have a maximum thickness of $6 \mathrm{~nm}^{18}$ ) or because of the accelerated redox between the active material and the electrolyte in which the SPI cannot fully overcome. Hence, a further passivating method such as coating would be required. After several cycling, similar SPI is observed in both coated and uncoated cases. This indicate that the SPI is stabilized after several cycles in the uncoated sample as well, though the performance of the battery is deteriorated because of the depletion of the active material. Nonetheless, to precisely realize the ineffectiveness of the SPI layer, in these cases, further studies especially with precise galvanostatic measurement would be required which can be of interest of the physical chemistry community.

\section{ASSOCIATED CONTENT}

\section{SI Supporting Information}

The Supporting Information is available free of charge at https://pubs.acs.org/doi/10.1021/acs.jpcc.0c08449.

Scanning electron microscopy and electrochemical properties of the samples (PDF)

\section{AUTHOR INFORMATION}

\section{Corresponding Author}

S. J. Rezvani - Sez. Fisica, Scuola di Scienze e Tecnologie, Universitá di Camerino, I-62032 Camerino, Italy; IOM, CNR at Elettra-Sincrotrone Trieste S. C. p. A., 34149 Basovizza, Italy; ○ orcid.org/0000-0002-6771-170X; Email: sj.rezvani@unicam.it

\section{Authors}

R. Parmar - Sez. Fisica, Scuola di Scienze e Tecnologie, Universitá di Camerino, I-62032 Camerino, Italy

F. Maroni - Accumulators Materials Research, Zentrum für Sonnenenergie-und Wasserstoff-Forschung BadenWürttemberg (ZSW), 89081 Ulm, Germany

F. Nobili - Sez. Chimica, Scuola di Scienze e Tecnologie, Universita di Camerino, I-62032 Camerino, Italy

A. Di Cicco - Sez. Fisica, Scuola di Scienze e Tecnologie, Universitá di Camerino, I-62032 Camerino, Italy

R. Gunnella - Sez. Fisica, Scuola di Scienze e Tecnologie, Universitá di Camerino, I-62032 Camerino, Italy; (1) orcid.org/0000-0003-4739-6375

Complete contact information is available at:

https://pubs.acs.org/10.1021/acs.jpcc.0c08449

\section{Notes}

The authors declare no competing financial interest.

\section{ACKNOWLEDGMENTS}

We would like to thank S. Nannarone and A. Giglia for valuable assistance in XAS measurements.

\section{REFERENCES}

(1) Peled, E. The Electrochemical Behavior of Alkali and Alkaline Earth Metals in Nonaqueous Battery Systems-The Solid Electrolyte Interphase Model. J. Electrochem. Soc. 1979, 126, 2047.
(2) Peled, E.; Golodnitsky, D.; Ardel, G. Advanced Model for Solid Electrolyte Interphase Electrodes in Liquid and Polymer Electrolytes. J. Electrochem. Soc. 2019, 144, L208-L210.

(3) Rezvani, S. J.; Ciambezi, M.; Gunnella, R.; Minicucci, M.; Muñoz, M. A.; Nobili, F.; Pasqualini, M.; Passerini, S.; Schreiner, C.; Trapananti, A.; Witkowska, A.; Di Cicco, A. Local Structure and Stability of SEI in Graphite and ZFO Electrodes Probed by As K-Edge Absorption Spectroscopy. J. Phys. Chem. C 2016, 120, 4287-4295.

(4) Rezvani, S. J.; Nobili, F.; Gunnella, R.; Ali, M.; Tossici, R.; Passerini, S.; Di Cicco, A. SEI Dynamics in Metal Oxide Conversion Electrodes of Li-Ion Batteries. J. Phys. Chem. C 2017, 121, 2637926388.

(5) Attia, P. M.; Das, S.; Harris, S. J.; Bazant, M. Z.; Chueh, W. C. Electrochemical Kinetics of SEI Growth on Carbon Black: Part I. Experiments. J. Electrochem. Soc. 2019, 166, E97-E106.

(6) Song, J.; Xiao, B.; Lin, Y.; Xu, K.; Li, X. Interphases in SodiumIon Batteries. Adv. Energy Mater. 2018, 8, 1703082.

(7) Raguette, L.; Jorn, R. Ion Solvation and Dynamics at Solid Electrolyte Interphases: A Long Way from Bulk? J. Phys. Chem. C 2018, 122, 3219-3232.

(8) Bruce, P. G.; Scrosati, B.; Tarascon, J.-M. Nanomaterials for Rechargeable Lithium Batteries. Angew. Chem., Int. Ed. 2008, 47, 2930-2946.

(9) Pinto, N.; Rezvani, S. J.; Favre, L.; Berbezier, I.; Fretto, M.; Boarino, L. Geometrically induced electron-electron interaction in semiconductor nanowires. Appl. Phys. Lett. 2016, 109, 123101.

(10) Rezvani, S. J.; Gunnella, R.; Neilson, D.; Boarino, L.; Croin, L.; Aprile, G.; Fretto, M.; Rizzi, P.; Antonioli, D.; Pinto, N. Effect of carrier tunneling on the structure of $\mathrm{Si}$ nanowires fabricated by metal assisted etching. Nanotechnology 2016, 27, 345301.

(11) Liu, C.; Neale, Z. G.; Cao, G. Understanding electrochemical potentials of cathode materials in rechargeable batteries. Mater. Today 2016, 19, 109-123.

(12) Pasqualini, M.; Calcaterra, S.; Maroni, F.; Rezvani, S. J.; Di Cicco, A.; Alexander, S.; Rajantie, H.; Tossici, R.; Nobili, F. Electrochemical and spectroscopic characterization of an aluminacoated LiMn2O4 cathode with enhanced interfacial stability. Electrochim. Acta 2017, 258, 175-181.

(13) Secchiaroli, M.; Calcaterra, S.; Tran, H. Y.; Rezvani, S. J.; Nobili, F.; Marassi, R.; Wohlfahrt-Mehrens, M.; Dsoke, S. Development of non-fluorinated cathodes based on $\mathrm{Li}_{3} \mathrm{~V}_{1.95} \mathrm{Ni}_{0.05}\left(\mathrm{PO}_{4}\right)_{3} / \mathrm{C}$ with prolonged cycle life: A comparison among na-alginate, nacarboxymethyl cellulose and poly(acrylic acid) binders. J. Electrochem. Soc. 2017, 164, A672.

(14) Rezvani, S. J.; Mijiti, Y.; Gunnella, R.; Nobili, F.; Trapananti, A.; Minicucci, M.; Ciambezi, M.; Bresser, D.; Nannarone, S.; Passerini, S.; Di Cicco, A. Structure rearrangements induced by lithium insertion in metal alloying oxide mixed spinel structure studied by x-ray absorption near-edge spectroscopy. J. Phys. Chem. Solids 2020, 136, 109172.

(15) Minicucci, M.; Tabassam, L.; Natali, R.; Mancini, G.; Rezvani, S. J.; Di Cicco, A. Double-edge X-ray absorption study of LiFe1-xNixPO4 cathode materials. J. Mater. Sci. 2017, 52, 48864893.

(16) Julien, C. M.; Massot, M. Raman spectroscopic studies of lithium manganates with spinel structure. J. Phys.: Condens. Matter 2003, 15, 3151-3162.

(17) Ramana, C. V.; Massot, M.; Julien, C. M. XPS and Raman spectroscopic characterization of LiMn2O4 spinels. Surf. Interface Anal. 2005, 37, 412-416.

(18) Parmar, R.; Rezvani, S. J.; Nobili, F.; Di Cicco, A.; Trapananti, A.; Minicucci, M.; Nannarone, S.; Giglia, A.; Maroni, F.; Gunnella, R. Electrochemical response and structural stability of the $\mathrm{Li}+$ ion battery cathode with coated LiMn2O4 nanoparticles. ACS Appl. Energy Mater. 2020, 3, 8356.

(19) Julien, C.; Mauger, A.; Zaghib, K.; Groult, H. Comparative Issues of Cathode Materials for Li-Ion Batteries. Inorganics 2014, 2, $132-154$. 
(20) Blyr, A.; Sigala, C.; Amatucci, G.; Guyomard, D.; Chabre, Y.; Tarascon, J. M. Self-Discharge of LiMn2 O 4/C Li-Ion Cells in Their Discharged State: Understanding by Means of Three-Electrode Measurements. J. Electrochem. Soc. 1998, 145, 194.

(21) Bresser, D.; Paillard, E.; Kloepsch, R.; Krueger, S.; Fiedler, M.; Schmitz, R.; Baither, D.; Winter, M.; Passerini, S. Carbon Coated ZnFe2O4Nanoparticles for Advanced Lithium-Ion Anodes. Adv. Energy Mater. 2013, 3, 513-523.

(22) Di Cicco, A.; Giglia, A.; Gunnella, R.; Koch, S. L.; Mueller, F.; Nobili, F.; Pasqualini, M.; Passerini, S.; Tossici, R.; Witkowska, A. SEI Growth and Depth Profiling on ZFO Electrodes by Soft X-Ray Absorption Spectroscopy. Adv. Energy Mater. 2015, 5, 1500642.

(23) Rezvani, S. J.; Gunnella, R.; Witkowska, A.; Mueller, F.; Pasqualini, M.; Nobili, F.; Passerini, S.; Cicco, A. D. Is the Solid Electrolyte Interphase an Extra-Charge Reservoir in Li-Ion Batteries? ACS Appl. Mater. Interfaces 2017, 9, 4570-4576.

(24) Kim, J.-H.; Pieczonka, N. P. W.; Li, Z.; Wu, Y.; Harris, S.; Powell, B. R. Understanding the capacity fading mechanism in LiNi0.5Mn1.5O4/graphite Li-ion batteries. Electrochim. Acta 2013, $90,556-562$.

(25) Liu, J.; Manthiram, A. Functional surface modifications of a high capacity layered $\mathrm{Li}[\mathrm{Li} 0.2 \mathrm{Mn} 0.54 \mathrm{Ni} 0.13 \mathrm{Co} 0.13] \mathrm{O} 2$ cathode. $J$. Mater. Chem. 2010, 20, 3961-3967.

(26) Lenardi, C.; Piseri, P.; Briois, V.; Bottani, C. E.; Bassi, A. L.; Milani, P. Near-edge x-ray absorption fine structure and Raman characterization of amorphous and nanostructured carbon films. J. Appl. Phys. 1999, 85, 7159-7167.

(27) Comelli, G.; Stöhr, J.; Robinson, C. J.; Jark, W. Structural studies of argon-sputtered amorphous carbon films by means of extended x-ray-absorption fine structure. Phys. Rev. B: Condens. Matter Mater. Phys. 1988, 38, 7511-7519.

(28) Augustsson, A.; Herstedt, M.; Guo, J.-H.; Edström, K.; Zhuang, G. V.; Ross, P. N., Jr; Rubensson, J.-E.; Nordgren, J. Solid electrolyte interphase on graphite Li-ion battery anodes studied by soft X-ray spectroscopy. Phys. Chem. Chem. Phys. 2004, 6, 4185-4189.

(29) Rezvani, S. J.; Pasqualini, M.; Witkowska, A.; Gunnella, R.; Birrozzi, A.; Minicucci, M.; Rajantie, H.; Copley, M.; Nobili, F.; Di Cicco, A. Binder-induced surface structure evolution effects on Li-ion battery performance. Appl. Surf. Sci. 2018, 435, 1029-1036.

(30) Gireaud, L.; Grugeon, S.; Pilard, S.; Guenot, P.; Tarascon, J.M.; Laruelle, S. Mass Spectrometry Investigations on Electrolyte Degradation Products for the Development of Nanocomposite Electrodes in Lithium Ion Batteries. Anal. Chem. 2006, 78, 36883698.

(31) Aoki, A. X-Ray Photoelectron Spectroscopic Studies on ZnS: MnF2Phosphors. Jpn. J. Appl. Phys. 1976, 15, 305-311.

(32) Tsuji, J.; Nakamatsu, H.; Mukoyama, T.; Kojima, K.; Ikeda, S.; Taniguchi, K. Lithium K-edge XANES spectra for lithium compounds. X-Ray Spectrom. 2002, 31, 319-326.

(33) Boesenberg, U.; Marcus, M. A.; Shukla, A. K.; Yi, T.; McDermott, E.; Teh, P. F.; Srinivasan, M.; Moewes, A.; Cabana, J. Asymmetric pathways in the electrochemical conversion reaction of $\mathrm{NiO}$ as battery electrode with high storage capacity. Sci. Rep. 2014, 4, 7133.

(34) Guglieri, C.; Chaboy, J. O K-Edge X-ray Absorption Spectroscopy in Al-Doped $\mathrm{ZnO}$ Materials: Structural vs Electronic Effects. J. Phys. Chem. C 2014, 118, 25779-25785.

(35) Noh, H.-J.; Yeo, S.; Kang, J.-S.; Zhang, C. L.; Cheong, S.-W.; Oh, S.-J.; Johnson, P. D. Jahn-Teller effect in spinel manganites probed by soft x-ray absorption spectroscopy. Appl. Phys. Lett. 2006, $88,081911$.

(36) Gilbert, B.; Frazer, B. H.; Belz, A.; Conrad, P. G.; Nealson, K. H.; Haskel, D.; Lang, J. C.; Srajer, G.; De Stasio, G. Multiple Scattering Calculations of Bonding and X-ray Absorption Spectroscopy of Manganese Oxides. J. Phys. Chem. A 2003, 107, 2839-2847.

(37) Kawai, J.; Yamamoto, T.; Harada, Y.; Shin, S. Fluorine K $\alpha$ Xray fluorescence spectra of $\mathrm{MnF} 2$ excited at threshold. Solid State Commun. 1998, 105, 381-385.
(38) Qiao, R.; Chin, T.; Harris, S. J.; Yan, S.; Yang, W. Spectroscopic fingerprints of valence and spin states in manganese oxides and fluorides. Curr. Appl. Phys. 2013, 13, 544-548.

(39) Chung, K. Y.; Yoon, W.-S.; Kim, K.-B.; Cho, B.-W.; Yang, X.-Q. Formation of an SEI on a LiMn2O4 cathode during room temperature charge-discharge cycling studied by soft X-ray absorption spectroscopy at the Fluorine K-edge. J. Appl. Electrochem. 2011, 41, 1295.

(40) Hwang, S.-J.; Park, H.-S.; Choy, J.-H.; Campet, G.; Portier, J.; Kwon, C.-W.; Etourneau, J. Micro-Raman Spectroscopic Study on Layered Lithium Manganese Oxide and Its Delithiated/Relithiated Derivatives. Electrochem. Solid-State Lett. 2001, 4, A213.

(41) Hwang, S.-J.; Park, D.-H.; Choy, J.-H.; Campet, G. Effect of Chromium Substitution on the Lattice Vibration of Spinel Lithium Manganate: A New Interpretation of the Raman Spectrum of LiMn2O4. J. Phys. Chem. B 2004, 108, 12713-12717.

(42) Hunter, J. C. Preparation of a new crystal form of manganese dioxide: $\lambda$-MnO2. J. Solid State Chem. 1981, 39, 142-147.

(43) Cabo-Fernandez, L.; Mueller, F.; Passerini, S.; Hardwick, L. J. In situ Raman spectroscopy of carbon-coated $\mathrm{ZnFe} 2 \mathrm{O} 4$ anode material in Li-ion batteries - investigation of SEI growth. Chem. Commun. 2016, 52, 3970-3973. 